\title{
Male-female concordance in reported involvement of women in contraceptive decision-making and its association with modern contraceptive use among couples in rural Maharashtra, India
}

Anvita Dixit ${ }^{1,2^{*}} \mathbb{D}$, Nicole E. Johns ${ }^{1}$, Mohan Ghule ${ }^{1}$, Madhusudana Battala ${ }^{3}$, Shahina Begum ${ }^{4}$, Jennifer Yore ${ }^{1}$, Niranjan Saggurti ${ }^{3}$, Jay G. Silverman ${ }^{1}$, Elizabeth Reed ${ }^{1,5}$, Tarik Benmarhnia ${ }^{6,7}$, Sarah Averbach ${ }^{1,8}$ and Anita Raj ${ }^{1,9}$

\begin{abstract}
Objective: Women's involvement in contraceptive decision-making increases contraceptive use and reduces unmet need, but study of this has been limited to women's self-reports. Less research is available examining couple concordance and women's involvement in contraceptive decision-making as reported by both men and women.

Study design: We carried out a cross-sectional study using data from rural India ( $N=961$ young married couples). Using multivariable regression we examined the association between concordance or discordance in spousal reports of wife's involvement in contraceptive decision-making and modern contraceptive use, adjusting for demographics, intimate partner violence, and contraceptive use discussion.

Results: More than one third (38.3\%) of women reported current modern contraceptive use. Report of women's involvement in contraceptive decision-making showed $70.3 \%$ of couples agreed that women were involved, jointly or alone (categorized as Concordant 1), 4.2\% agreed women were not involved (categorized at Concordant 2), 13.2\% had women report involvement but men report women were uninvolved (categorized as Discordant 1), and 12.2\% had women report uninvolvement but men report that women were involved (categorized as Discordant 2). Discordant 2 couples had lower odds of modern contraceptive use relative to Concordant 1 couples (adjusted RR $=0.61,95 \%$ $\mathrm{Cl}$ 0.45-0.83). No other significant differences between Concordant 1 couples and other categories were observed.
\end{abstract}

Conclusion: One in four couples indicated discordance on women's involvement in contraceptive decision making, with Discordant 2 category having lower odds of contraceptive use. Couples' concordance in women's involvement in contraceptive decision-making offers a target for family planning research and interventions to better meet their needs.

Trial registration ClinicalTrial.gov, NCT03514914. https://clinicaltrials.gov/ct2/show/NCT03514914

\footnotetext{
*Correspondence: anvita.dixit@gmail.com

${ }^{1}$ Center on Gender Equity and Health, Division of Infectious Diseases

and Global Public Health, School of Medicine, University of California San

Diego, La Jolla, USA

Full list of author information is available at the end of the article
} permits use, sharing, adaptation, distribution and reproduction in any medium or format, as long as you give appropriate credit to the original author(s) and the source, provide a link to the Creative Commons licence, and indicate if changes were made. The images or other third party material in this article are included in the article's Creative Commons licence, unless indicated otherwise in a credit line to the material. If material is not included in the article's Creative Commons licence and your intended use is not permitted by statutory regulation or exceeds the permitted use, you will need to obtain permission directly from the copyright holder. To view a copy of this licence, visit http://creativecommons.org/licenses/by/4.0/. The Creative Commons Public Domain Dedication waiver (http://creativeco mmons.org/publicdomain/zero/1.0/) applies to the data made available in this article, unless otherwise stated in a credit line to the data. 


\begin{abstract}
Plain language summary
Evidence on women's involvement in decision-making are limited to women's self reports and often not specific to contraceptive decision-making. This study uses couples dyadic data to assess male-female concordance on women's involvement in contraceptive decision-making and contraceptive use outcomes. Couple's concordance on women's involvement in contraceptive decision-making is associated with contraceptive use. There is potential in couplefocused family planning counseling that enhances women's contraceptive decision-making agency to improve women's contraceptive use.
\end{abstract}

Keywords: Contraceptive decision-making, Couple concordance, Contraceptive use, Dyadic data, India

\section{Background}

India is home to $20 \%$ of the world's married couples with unmet need for contraceptives, with an estimated 50\% of all pregnancies being unintended [1, 2]. Contraceptive use can prevent unintended pregnancy and reduce maternal and child morbidity and mortality [3-5]. Some evidence suggests that women's control over reproductive decision-making is associated with increased likelihood of contraceptive use in India, though there have been mixed results across studies and other nations [6-10]. This may be a result of women's control being assessed using women's self-report only, but couples' contraceptive decision-making can be better understood by assessing both women and their husbands' reports. Growing evidence suggests that when couples agree on women's involvement in decision-making generally, the wife's healthcare utilization is increased compared to when they disagree [11]. Studies of couples' dyadic data suggest that balance of power between male and female partners in a couple may improve shared decision-making practices than women's individual decision-making agency alone $[9,12-16]$. However, little research exists examining contraceptive decision-making agency as measured by dyadic couples' reports.

Men are often the decision-makers for fertility-related issues in India, including contraceptive use [17-20]. Interventions aimed at engaging men in couples' reproductive health care have been shown to improve contraceptive uptake [19, 21]. Wife's communication with husband and husbands support of contraceptive use are both associated with improved joint family planning decision-making in these studies [19, 21-23]. However, interventions designed to engage men in contraceptive decision-making have primarily focused on increasing male involvement in family planning, but have not directly addressed women's perceived decision-making agency. Examination of women's perceived decisionmaking agency, through their voice or involvement in the contraceptive decision-making process with their husbands, is warranted.

In this paper, we assess the association between women's perceived decision-making agency, as measured by couple's concordance of reporting women's involvement in contraceptive decision-making, and modern contraceptive use among women in rural India. We also consider the role of intent to use contraception, given the theoretical importance of behavioral intention to perform the outcome [24], and the fact that married women of reproductive age who want to avoid pregnancy and would intend to use contraception still report non-use of contraceptive methods $[25,26]$. We also explore the relationship between women's decision-making agency and women-led contraceptive use, by assessing the association of women's involvement in contraceptive decisionmaking with type of contraceptive method used.

\section{Methods \\ Sample}

We conducted a cross-sectional analysis using baseline dyadic data collected between September 2018 and June 2019 from the CHARM2 [Counseling Husbands and wives to Achieve Reproductive Health and Marital equity] intervention study of young women (18 to 29 years old) and their husbands in rural Junnar district, Maharashtra, India $(\mathrm{N}=1201)$. Gender matched interviews were carried out in-person separately with husbands and wives using electronic tablets lasting for about 40 minutes. CHARM2 is a two-arm cluster randomized controlled trial (RCT) to evaluate a gender-synchronized, gender-transformative family planning intervention. CHARM2 aims to increase uptake of contraceptives, prevent unintended pregnancy, and decrease interpersonal violence. Couples who were not currently married or cohabiting, or who were using a permanent contraceptive method, were not eligible to participate in the study, in order to meaningfully measure study outcomes, including contraceptive use and unintended pregnancy at follow up. The detailed protocol for this cluster-RCT is published elsewhere [27]. Participants were recruited from households in each of the 20 geographic clusters, with each cluster based on its attachment to a single public sub-health centre catchment area. We then randomized to intervention or control condition at the cluster level; all clusters were identified and randomized prior to study 
recruitment. The analytic dataset for the current study excluded couples with currently pregnant wives $(n=199)$ and missing information on decision-making $(\mathrm{n}=36)$. Additionally, one couple missing demographic information and couples using uncommon methods (injectable contraceptive $(n=3)$ and emergency contraceptive pill $(n=1)$ were excluded, for a final sample of 961 couples. The University of California San Diego, ICMR-National Institute for Research in Reproductive Health in India, and the Population Council obtained approval from their respective IRBs for the protocol.

\section{Measures}

The primary outcome of interest was women's report of any current modern contraceptive method (dichotomized as yes/no) based on past three months use. Modern contraceptive methods included were oral contraceptive pills, Intrauterine Devices (IUDs), and male condoms [28]. Our survey included all types of contraceptives that were available in the study area as response options, though only condoms, pills, IUDs, and emergency contraceptive pill are modern spacing methods covered under the public health system. For assessing the association between couples' concordance on women's contraceptive decision-making agency and women led contraceptive use, methods included were non-modern (withdrawal and rhythm), male condoms, pills and IUDs, where use of pills and IUDs can be considered as women led.

The primary exposure of interest was couples' perceived women's contraceptive decision-making agency, and included both wife and husband's report of wife's involvement in contraceptive decision-making. Both members were asked, "Would you say that using or not using contraception is: mainly your decision, your husband's/wife's, joint by both husband and wife, your mother, mother in law, elderly head of household, your sibling, your husband's/wife's sibling or someone else?" The responses were collapsed into four categories of decision-making including woman alone, husband alone, wife and husband jointly, or others. The final couples' concordance/discordance on women's involvement in contraceptive decision-making variable was constructed combining husband and wife reports into four categories of contraceptive decision-making:

- Concordant 1 (women and men in agreement): Both agree women were involved (women only or joint decision-making)

- Concordant 2: Both agree that women were uninvolved (men only or others decided).

- Discordant 1: Women report women were involved and men report women were uninvolved
- Discordant 2: Women report women were uninvolved and men report women were involved

Additional variables included a priori as confounders based on previous literature and author expertise were: wife's age, wife's education (none or primary, secondary or higher), husband's age, husband's education (none or primary, secondary or higher), caste (General, Scheduled Caste/Scheduled Tribe/Other Backward Castes), religion (Hindu, non-Hindu), parity (0, 1, 2-4), any living sons (Yes, No), fertility desires (Have a/another child, No more/none, Undecided/ Don't know), Below Poverty Line card holder (Yes, No), and wife's age at marriage. In addition, we included women's report of ever experience of intimate partner violence (physical and/or sexual), wife's knowledge of contraceptive methods (number of methods), husbands knowledge of contraceptive methods, and couple concordance of contraceptive discussion in the past 3 months (both yes, both no, Wife yes/Husband no, Wife no/Husband yes). For assessing intention to use, women and men were asked: "Will you use a contraceptive method or continue to use one in the next 3 months to avoid or delay pregnancy?" with a yes/no response.

\section{Analysis}

Descriptive frequencies and proportions were calculated. Multivariable Poisson regression was used to model the relationship between women's involvement in contraceptive decision-making (reference group: Concordant 1) with modern contraception use for all women, in both an unadjusted and adjusted model for all potential confounders listed above. A Poisson regression with robust variance estimation for confidence intervals was carried out to limit possible inflation in the effect size relative to logistic regression, since the outcome is not rare (modern contraceptive use is greater than $10 \%$ in this sample) $[29,30]$. All comparison contrasts (comparing Discordant 2 with Concordant 2, Discordant 2 to Concordant 1, and Concordant 1 to Concordant 2) in both unadjusted and adjusted models are reported in Additional file 1: Table S2.

An exploratory analysis to examine contraceptive use intention was carried out with the multivariable model, adjusting for women's intention to use modern contraceptives (Additional file 1: Table S3 M2), and then men's intention to use modern contraceptives (Additional file 1: Table S3 M3). Further, an equivalent multinomial logistic regression was carried out with categorical type of contraceptive use as the outcome.

As a sensitivity analysis (Additional file 1: Table S1), a propensity score adjusted Poisson regression was carried out to limit possible selection bias from the observational 
design of the study. All analyses were conducted using STATA version 14.0 [31].

\section{Results}

A reported $38.3 \%$ of wives were using modern contraception: $25.7 \%$ were using male condoms, $3.2 \%$ pills and $9.1 \%$ IUDs. In $70.3 \%$ of couples both husband and wife reported that the wife is involved in contraceptive decision-making (Concordant 1 ) and in $4.2 \%$ of couples both husband and wife report that the wife is uninvolved (Concordant 2). Discordance in wife involvement in decision-making was reported by $25.4 \%$ of couples, with $13.2 \%$ of husbands reporting their wife is uninvolved, while the wife reports she is involved (Discordant 1), and $12.2 \%$ of husbands reporting that the wife is involved while the wife reports she is uninvolved (Discordant 2) (Table 1).

Adjusted multivariable analysis showed that couples in the Discordant 2 category for contraceptive decisionmaking (women report women were uninvolved and men report women were involved), had lower odds of reported modern contraceptive use relative to Concordant 1 (women and men agree that women were involved) couples (adjusted $R R=0.61,95 \%$ CI $0.45-0.83$ ), after adjusting for confounders (Table 2). None of the remaining categories of couple concordance on women's involvement in contraceptive decision-making were significantly associated with the outcome. Exploratorily, we also adjusted for women's intention to use modern contraceptives, and found that the association of Discordant 2 category for contraceptive decision making with modern contraceptive use relative to Concordant 1 couples was lost. However, once we adjusted for men's intention to use modern contraceptives, couples in the Discordant 2 category for contraceptive decision-making (women report women were uninvolved and men report women were involved) had lower odds of modern contraceptive use relative to Concordant 1 couples (Additional file 1: Table S3 M3: adjusted RR $=0.61,95 \%$ CI 0.45-0.83), findings comparable to our main findings on Discordant 2 couples. The sensitivity analysis showed that the Poisson adjusted regression with propensity scores did not substantially differ from the adjusted Poisson regression findings, computing a similar magnitude estimate as seen in our main findings (adjusted $\mathrm{RR}=0.51,95 \% \mathrm{CI}=0.36$ 0.73) (Additional file 1: Table S2).

In the multinomial logistic regression with type of contraceptive used as the outcome, Discordant 2 couples had lower odds of reporting condom use and IUD use relative to Concordant 1 couples (Condoms: $\mathrm{AOR}=0.49,95 \%$ CI $0.26-0.92$, and IUD: $\mathrm{AOR}=0.37,95 \%$ CI $0.16-0.89$ ), after adjusting for confounders (Table 3). There were no observed relationships between decision-making concordance and non-modern (withdrawal and rhythm) methods or pill use.

\section{Discussion}

One in three couples reported that women were either not involved or had discordant views on women's involvement in contraceptive decision-making (i.e. they reported Concordant 2, Discordant 1 or Discordant 2). This highlights that many women are not involved in contraceptive decision-making, and many couples are not on the same page about women's involvement in this decision-making. Discordant 2 couples, where women report women were uninvolved and men report women were involved, had lower odds of contraceptive use compared to Concordant 1 couples, where men and women both agree that women were involved in contraceptive decisionmaking. One in nine women in our sample report no contraceptive decision-making control while their husbands disagree reporting that their wife is involved. This suggests that some spouses may believe the other to be in control of contraceptive decisions when in fact neither is engaged. This also suggests that some women do not know or do not act on their reproductive agency when their husbands indicate they have it. This could reflect several realities, including poor communication, dismpowerment for the women, or abdication of responsibility by the husbands on contraceptive decision-making.

Although, previous studies assessing women's responses to contraceptive decision-making suggest that increasing women's reported agency alone may increase contraceptive use [10], couples concordant report of wife-involved decision-making did not show increased contraceptives use in our sample. On the other hand, couples where women report being uninvolved but men report their wives were involved in decision-making had lower odds of contraceptive use. Comparably, a study of couples' household decision-making and contraceptive use in Bangladesh suggests that a balance in power, rather than wife only decision-making, may have the most impactful outcomes [9]. Furthermore, the association was not explained by socio-demographic correlates, and only a small part of this association is explained by spousal communication about contraceptives. Couple concordance in report of recent contraceptive discussion was significantly associated with increased modern contraceptive use. In India, greater women's empowerment has previously been reported among couples who are concordant in their reporting of contraceptive communication and use [12]. Thus, couple communication may explain discordance in decision-making further and should be considered in furture research.

Among Discordant 2 couples (women report women uninvolved and men report women involved), when 
Table 1 Sociodemographic characteristics of married couples enrolled in CHARM2 in rural Maharashtra, India ( $\mathrm{N}=961)$

\begin{tabular}{|c|c|c|c|}
\hline \multirow[t]{2}{*}{ Variable } & \multirow[t]{2}{*}{ Overall, n (\%) } & \multicolumn{2}{|c|}{ Current modern FP use } \\
\hline & & Yes, $\mathrm{n}(\%)$ & No, n (\%) \\
\hline \multicolumn{4}{|l|}{ Modern contraceptive use (3 mo) } \\
\hline Yes & $368(38.29 \%)$ & - & - \\
\hline No & $593(61.71 \%)$ & - & - \\
\hline \multicolumn{4}{|l|}{ Type of contraceptive used (3 mo) $(\mathrm{N}=958)$} \\
\hline None & $372(38.83 \%)$ & - & - \\
\hline Withdrawal or rythm & $222(23.17 \%)$ & - & - \\
\hline Male condoms & $246(25.68 \%)$ & - & - \\
\hline Pills & $31(3.24 \%)$ & - & - \\
\hline IUDs & $87(9.08 \%)$ & - & - \\
\hline \multicolumn{4}{|l|}{ Couple concordance on contraceptive decision-making } \\
\hline Concordant 1 (women and men agreement): Women-Involved (women only or joint) & $676(70.34 \%)$ & $285(77.45 \%)$ & $391(65.94 \%)$ \\
\hline Concordant 2: Women Uninvolved (men only or other) & $40(4.16 \%)$ & $11(2.99 \%)$ & $29(4.89 \%)$ \\
\hline Discordant 1: Women-Report Women Involved and Men-Report Women Uninvolved & $127(13.22 \%)$ & $46(12.50 \%)$ & $81(13.66 \%)$ \\
\hline Discordant 2: Women-Report Women Uninvolved and Men-Report Women Involved & $1198(12.22 \%)$ & $26(7.07 \%)$ & $92(15.51 \%)$ \\
\hline Age in years (Mean, SD) & $24.11(2.92)$ & $24.58(2.85)$ & $23.83(2.94)$ \\
\hline Age at marriage in years (Mean, SD) & $19.42(2.36)$ & $19.49(2.33)$ & $19.38(2.39)$ \\
\hline Husband's age in years (Mean, SD) & $29.65(3.70)$ & $30.12(3.72)$ & $29.35(3.66)$ \\
\hline \multicolumn{4}{|l|}{ Education } \\
\hline No education + Primary & $138(14.36 \%)$ & 45 (12.23\%) & $93(15.68 \%)$ \\
\hline Secondary or higher & $823(85.64 \%)$ & $323(87.77 \%)$ & $500(84.32 \%)$ \\
\hline \multicolumn{4}{|l|}{ Husband's education } \\
\hline No education + Primary & $134(13.94 \%)$ & $44(11.96 \%)$ & $90(15.18 \%)$ \\
\hline Secondary or higher & $827(86.06 \%)$ & $324(88.04 \%)$ & $503(84.82 \%)$ \\
\hline \multicolumn{4}{|l|}{ Religion } \\
\hline Hindu & 893 (92.92\%) & $336(91.30 \%)$ & $557(93.93 \%)$ \\
\hline Other* & $68(7.08 \%)$ & $32(8.70 \%)$ & $36(6.07 \%)$ \\
\hline \multicolumn{4}{|l|}{ Caste } \\
\hline General & $652(67.85 \%)$ & $261(71.92 \%)$ & $391(65.94 \%)$ \\
\hline $\mathrm{SC} / \mathrm{ST} / \mathrm{OBC} C^{* *}$ & $309(32.15 \%)$ & $107(29.08 \%)$ & $202(34.06 \%)$ \\
\hline \multicolumn{4}{|l|}{ Below Poverty Line (BPL) card holder } \\
\hline Yes & $240(24.97 \%)$ & $86(23.37 \%)$ & $154(25.97 \%)$ \\
\hline No & $721(75.03 \%)$ & $282(76.63 \%)$ & $439(74.03 \%)$ \\
\hline \multicolumn{4}{|l|}{ Parity } \\
\hline 0 & $104(10.82 \%)$ & $13(3.53 \%)$ & $91(15.35 \%)$ \\
\hline 1 & $534(55.57 \%)$ & $214(58.15 \%)$ & $320(53.96 \%)$ \\
\hline $2-5$ & $323(33.61 \%)$ & $141(38.32 \%)$ & $182(30.69 \%)$ \\
\hline \multicolumn{4}{|l|}{ Any living sons } \\
\hline Yes & $492(51.20 \%)$ & $208(56.52 \%)$ & $284(47.89 \%)$ \\
\hline No & $469(48.80 \%)$ & $160(43.48 \%)$ & $309(52.11 \%)$ \\
\hline \multicolumn{4}{|l|}{ Fertility desires } \\
\hline Have a/another child & 573 (59.63\%) & $200(54.35 \%)$ & $373(62.90 \%)$ \\
\hline No more/none & $314(32.67 \%)$ & $135(36.68 \%)$ & $179(30.19 \%)$ \\
\hline Undecided/Don't know & $74(7.70 \%)$ & $33(8.97 \%)$ & $41(6.91 \%)$ \\
\hline $\begin{array}{l}\text { Knowledge of contraceptive methods } \\
\text { (Mean, Range) }\end{array}$ & $4.19(0-12)$ & 4.50 & 4.00 \\
\hline $\begin{array}{l}\text { Husband's knowledge of contraceptive methods } \\
\text { (Mean, Range) }\end{array}$ & $4.12(0-11)$ & 4.20 & 4.07 \\
\hline \multicolumn{4}{|l|}{ IPV (Physical or Sexual)*** } \\
\hline Yes & 109 (11.34\%) & $34(9.24 \%)$ & 75 (12.65\%) \\
\hline
\end{tabular}


Table 1 (continued)

\begin{tabular}{|c|c|c|c|}
\hline \multirow[t]{2}{*}{ Variable } & \multirow[t]{2}{*}{ Overall, n (\%) } & \multicolumn{2}{|c|}{ Current modern FP use } \\
\hline & & Yes, n (\%) & No, n (\%) \\
\hline No & $852(88.66 \%)$ & $334(90.76 \%)$ & $518(87.35 \%)$ \\
\hline \multicolumn{4}{|c|}{ Couple concordance on contraceptive discussion } \\
\hline Both yes & $247(25.70 \%)$ & $155(42.12 \%)$ & $92(15.51 \%)$ \\
\hline Both no & $261(27.16 \%)$ & $42(11.41 \%)$ & $219(36.93 \%)$ \\
\hline Wife yes/Husband no & $111(11.55 \%)$ & $56(15.22 \%)$ & 55 (9.27\%) \\
\hline Wife no/Husband yes & $342(35.59 \%)$ & $115(31.25 \%)$ & $227(38.28 \%)$ \\
\hline \multicolumn{4}{|c|}{ Intention to use modern contraceptive in $3 \mathrm{mo}$} \\
\hline Yes & $484(50.36 \%)$ & $349(94.84 \%)$ & $135(22.77 \%)$ \\
\hline No & 477 (49.64\%) & $19(5.16 \%)$ & $458(77.23 \%)$ \\
\hline Total N & $961(100 \%)$ & $368(100 \%)$ & $593(100 \%)$ \\
\hline
\end{tabular}

Table 2 Unadjusted and adjusted poisson regression between couple concordance of women's involvement in contraceptive decision making and current modern contraceptive use among married couples enrolled in CHARM2 in rural Maharashtra, India $(\mathrm{N}=961)$

\begin{tabular}{lll}
\hline Variable & Unadjusted & Adjusted \\
\hline Couple concordance of women's involvement in contraceptive decision making & RR (95\% Cl) & RR (95\% Cl) \\
Concordant 1 (women and men agreement): Women-Involved (women only or joint) & ref & ref \\
Concordant 2: Women Uninvolved (men only or other) & $0.64(0.39-1.04)$ & $0.79(0.54-1.18)$ \\
Discordant 1: Women-Report Women Involved and Men-Report Women Uninvolved & $0.82(0.64-1.05)$ & $0.82(0.66-1.02)$ \\
Discordant 2: Women-Report Women Uninvolved and Men-Report Women Involved & 0.52 (0.38-0.72) & 0.61 (0.45-0.83)
\end{tabular}

Adjusted for age, age at marriage, husbands age, education, husband's education, caste, religion, parity, any living sons, and Below Poverty Line status, knowledge of family planning methods, fertility desires, husband's knowledge of family planning methods, physical or sexual IPV, and concordance of FP discussion. ORs in bold represent statistically significant difference at $95 \%$ confidence interval

adjusted for women's intent to use (Additional file 1: Table S3 M2), an association was not noted with women's use of contraceptives. Whereas, when adjusted for men's intent to use, women had lower odds to use contraceptives (Additional file 1: Table S3 M3). Thus, contraceptive use intention plays an important role when men and women disagree on women's involvement in contraceptive decision-making. However, intention is a complex construct, assumed to be a conscious decision, but can be ambivalent and changing over time [32,33]. When we assessed the association with type of contraceptive used as the outcome, couples had lower odds to report using condoms and IUDs when women reported that they were not involved in decision-making, but men reported that women were involved (Discordant 2). Although, we expected low use of women-controlled methods, it is also critical for male controlled method of condoms and not specific to women-controlled methods. This highlights the need for women to be able to practice their contraceptive decision-making agency in partnership with men regardless of whether the contraceptive is women controlled or not.

The current study extends our understanding of women's contraceptive-specific agency by assessing both partners' report of decision-making, and adds to our understanding that increasing women's decision-making agency should be accompanied by engaging male partners when possible to optimally improve contraceptive utilization. This is highlighted by the association of discordant couples (Discordant 2) with lower modern contraceptive use. It is further emphasized by the importance of men's intention to use modern contraception rather than women's intention to use modern contraception. However, our findings should be considered in the context of several limitations. First, this is a cross-sectional analysis which precludes assumptions of causality. 
Table 3 Unadjusted and adjusted multinomial logistic regression between couple concordance of women's involvement in contraceptive decision making and type of contraceptive use among married couples enrolled in CHARM2 in rural Maharashtra, India $(\mathrm{N}=958)$

\begin{tabular}{|c|c|c|}
\hline Variable & $\begin{array}{l}\text { Unadjusted } \\
\text { OR }(95 \% \mathrm{CI})\end{array}$ & $\begin{array}{l}\text { Adjusted } \\
\text { AOR }(95 \% \mathrm{Cl})\end{array}$ \\
\hline \multicolumn{3}{|l|}{ Non-modern (withdrawal, rhythm) } \\
\hline Concordant 1 (women and men agreement): Women-Involved (women only or joint) & Ref & Ref \\
\hline Concordant 2: Women Uninvolved (men only or other) & $1.32(0.62-2.83)$ & $1.35(0.59-3.11)$ \\
\hline Discordant 1: Women-Report Women Involved and Men-Report Women Uninvolved & $1.01(0.62-1.65)$ & $0.84(0.49-1.42)$ \\
\hline Discordant 2: Women-Report Women Uninvolved and Men-Report Women Involved & $0.75(0.46-1.22)$ & $0.86(0.51-1.47)$ \\
\hline \multicolumn{3}{|l|}{ Male condoms } \\
\hline Concordant 1 (women and men agreement): Women-Involved (women only or joint) & Ref & Ref \\
\hline Concordant 2: Women Uninvolved (men only or other) & $0.75(0.32-1.74)$ & $0.98(0.38-2.52)$ \\
\hline Discordant 1: Women-Report Women Involved and Men-Report Women Uninvolved & $0.96(0.60-1.54)$ & $0.86(0.50-1.48)$ \\
\hline Discordant 2: Women-Report Women Uninvolved and Men-Report Women Involved & $0.40(\mathbf{0 . 2 3}-\mathbf{0 . 7 0})$ & $0.49(0.26-0.92)$ \\
\hline \multicolumn{3}{|l|}{ Pills } \\
\hline Concordant 1 (women and men agreement): Women-Involved (women only or joint) & Ref & Ref \\
\hline Concordant 2: Women Uninvolved (men only or other) & ** & $* *$ \\
\hline Discordant 1: Women-Report Women Involved and Men-Report Women Uninvolved & $0.52(0.15-1.78)$ & $0.34(0.09-1.29)$ \\
\hline Discordant 2: Women-Report Women Uninvolved and Men-Report Women Involved & $* *$ & ** \\
\hline \multicolumn{3}{|l|}{ IUD } \\
\hline Concordant 1 (women and men agreement): Women-Involved (women only or joint) & Ref & Ref \\
\hline Concordant 2: Women Uninvolved (men only or other) & $0.43(10-1.90)$ & $0.53(0.11-2.47)$ \\
\hline Discordant 1: Women-Report Women Involved and Men-Report Women Uninvolved & $0.48(0.21-1.10)$ & $0.42(0.18-1.00)$ \\
\hline Discordant 2: Women-Report Women Uninvolved and Men-Report Women Involved & $0.38(\mathbf{1 . 1 7}-\mathbf{0 . 8 7})$ & $0.37(\mathbf{0 . 1 6}-\mathbf{0 . 8 9})$ \\
\hline
\end{tabular}

Adjusted for age, age at marriage, husbands age, education, husband's education, caste, religion, parity, any living sons, and Below Poverty Line status, knowledge of family planning methods, fertility desires, husband's knowledge of family planning methods, physical or sexual IPV, and concordance of FP discussion. ORs in bold represent statistically significant difference at $95 \%$ confidence interval

Figures in bold indicate that the differences are statistically and significantly different from zero at the $95 \%$ confidence level

${ }^{* *}$ Empty cell could not be calculated

Responses were subject to social desirability bias, and some men may have erroneously reported that their wives were involved in contraceptive decision-making. The sample for this study is from participants enrolled in a RCT, and generalizability of the findings may be limited [27]. In particular, since the CHARM2 intervention aims at improving contraceptive use, only non-sterilized couples were included in the study and this sample, thus underestimating true contraceptive prevalence. Given the Indian context where female sterilization dominates $(63.9 \%$ of all) contraceptive use [26], our findings are relevant to decisions involving the use of short- and long-term reversible contraceptives (IUD, pills, and condoms) only. These are the only modern methods currently available in the public health system in India and the most common methods reported in the study sample. While it was exploratory, a low cell count limited our understanding of Concordant 2 group among those who do not intend to use contraceptives, and Concordant 2 and Discordant 2 groups among pill users in the multinomial analysis. Improved measurement of women's decision-making involvement is needed to advance our understanding of this complex construct [34]. Finally, although we used the same measures for husbands and wives', they may perceive and respond to them differently. Multi-national evidence suggests that men and women don't have the same cognitive or semantic understanding of response categories to survey questions on gender relations (35).

\section{Conclusion}

To conclude, supporting a more equitable balance of power between couples and encouraging couples' informed and respectful joint decision-making regarding contraceptive use is important, but may not be enough to create impact. Interventions need to focus on a) women's agency to be involved and be an active agent in contraceptive decision-making combined with b) male responsibility in family planning and their engagement in family planning programs. 


\begin{abstract}
Abbreviations
AOR: Adjusted odds ratio; BPL: Below poverty line; CHARM2: Counseling husbands and wives to achieve reproductive health and marital equity 2; $\mathrm{Cl}$ : Confidence interval; IUD: Intrauterine device; IPV: Intimate partner violence; OBC: Other backward caste; OR: Odds ratio; RCT: Randomized controlled trial; RR: Relative risk; SC: Scheduled caste; SD: Standard deviation; ST: Scheduled tribe.
\end{abstract}

\section{Supplementary Information}

The online version contains supplementary material available at https://doi. org/10.1186/s12978-021-01187-8.

Additional file 1: Table S1: Sensitivity analysis showing propensity score adjusted poisson regression for the association between couple concordance of women's involvement in contraceptive decision making and current modern contraceptive use among married couples enrolled in CHARM2 in rural Maharashtra, India $(\mathrm{N}=961)$.Table S2: Unadjusted and adjusted poisson regression for all category comparisons of the association between couple concordance of women's involvement in contraceptive decision making and current modern contraceptive use among married couples enrolled in CHARM2 in rural Maharashtra, India ( $\mathrm{N}=961)$.Table S3: Adjusted poisson regression between couple concordance of women's involvement in contraceptive decision making and current modern contraceptive use women's intention (M2), and men's intention (M3) to use modern FP in 3 months, among married couples enrolled in CHARM2 in rural Maharashtra, India $(\mathrm{N}=961)$.

\section{Acknowledgements}

We are grateful to the CHARM2 field research staff, the public and private healthcare providers and participants who have enrolled in our study. We thank National Innntittues of Health (R01-HD084453, PI: Raj; 5K12HD001259, PI: Averbach), and the Bill and Melinda Gates Foundation (\#INV-002967) for financial support. We are also thannkful for the opportunity to present these findings as a poster and incorporate feedback at the Society of Family Planning (SFP) Annual Meeting, October 19-21, 2019 in Los Angeles, USA.

\section{Authors' contributions}

$A D$ was a PhD candidate at the time of this study and lead this paper as part of her PhD dissertation. NEJ, MG, MB, SB, JY, NS, and SA are the CHARM2 study team and gave comments on the paper. $E R$, TB, and JS gave comments at conceptualization and design stage as well as reviewed the writing for the paper. AR is the Principal Investigator of the study, supporting conceptualization and design; she oversaw all substantive revisions of the work. All authors read and approved the final manuscript.

\section{Funding}

This work was funded by the National Institutes of Health US (Grant Number: R01-HD084453 and 5K12HD001259), and the Bill and Melinda Gates Foundation (Grant Number: INV-002967). The funding source had no role in study design, data collection and analysis, decision to publish, or preparation of the manuscript.

\section{Availability of data and materials}

Due to ethical restrictions regarding patient privacy, data are available upon request from geh@ucsd.edu with subject line "request for CHARM2 data". Data will be made publically available pending primary evaluation study publication after the end of CHARM2 study.

\section{Declarations}

\section{Ethics approval and consent to participate}

All participants gave their informed consent prior to interviews. The University of California San Diego, ICMR-National Institute for Research in Reproductive Health in India, and the Population Council obtained approval from their respective IRBs for the protocol.

\section{Consent for publication}

Not applicable.

\section{Competing interests}

The authors declare that they have no competing interests.

\section{Author details}

${ }^{1}$ Center on Gender Equity and Health, Division of Infectious Diseases and Global Public Health, School of Medicine, University of California San Diego, La Jolla, USA. ${ }^{2}$ Joint Doctoral Program in Public Health (Global Health Track), University of California San Diego/San Diego State University, San Diego, USA. ${ }^{3}$ Population Council, New Delhi, India. ${ }^{4}$ ICMR-National Institute for Research in Reproductive Health, Mumbai, India. ${ }^{5}$ Division of Health Promotion and Behavior, San Diego State University, San Diego, USA. ${ }^{6}$ Department of Family Medicine and Public Health, University of California, San Diego, USA. ${ }^{7}$ Scripps Institution of Oceanography, University of California, San Diego, USA. ${ }^{8}$ Department of Obstetrics, Gynecology, and Reproductive Sciences, School of Medicine, University of California San Diego, La Jolla, USA. ${ }^{9}$ Department of Education Studies, Division of Social Sciences, University of California San Diego, La Jolla, USA.

Received: 23 March 2021 Accepted: 21 June 2021

Published online: 30 June 2021

\section{References}

1. Singh S, Shekhar C, Acharya R, Moore AM, Stillman M, Pradhan MR, et al. The incidence of abortion and unintended pregnancy in India, 2015. Lancet Glob Health. 2018;6(1):e111-20.

2. Alkema L, Kantorova V, Menozzi C, Biddlecom A. National, regional, and global rates and trends in contraceptive prevalence and unmet need for family planning between 1990 and 2015: a systematic and comprehensive analysis. Lancet. 2013;381(9878):1642-52.

3. Gipson JD, Koenig MA, Hindin MJ. The effects of unintended pregnancy on infant, child, and parental health: a review of the literature. Stud Fam Plann. 2008;39(1):18-38.

4. Rutstein SO. Further evidence of the effects of preceding birth intervals on neonatal, infant, and under-five-years mortality and nutritional status in developing countries: evidence from the Demographic and Health Surveys. Calverton, MD: ORC Macro; 2008.

5. Singh S, Darroch JE, Ashford LS. Adding it up: The costs and benefits of investing in sexual and reproductive health 2014. New York: Guttmacher Institute; 2014

6. Prata N, Fraser A, Huchko MJ, Gipson JD, Withers M, Lewis S, et al. Women's empowerment and family planning: a review of literature. J Biosoc Sci. 2017;49(6):713-43.

7. Upadhyay UD, Karasek D. Women's empowerment and ideal family size: an examination of DHS empowerment measures in Sub-Saharan Africa. Int Perspect Sex Reprod Health. 2012;38(2):78-89.

8. Upadhyay UD, Gipson JD, Withers M, Lewis S, Ciaraldi EJ, Fraser A, et al. Women's empowerment and fertility: a review of the literature. Soc Sci Med. 1982;2014(115):111-20.

9. Uddin J, Hossin MZ, Pulok MH. Couple's concordance and discordance in household decision-making and married women's use of modern contraceptives in Bangladesh. BMC Womens Health. 2017;17(1):107.

10. Darteh EKM, Dickson KS, Doku DT. Women's reproductive health decisionmaking: a multi-country analysis of demographic and health surveys in sub-Saharan Africa. PLoS ONE. 2019;14(1): e0209985.

11. Allendorf K. Couples' reports of women's autonomy and health-care use in Nepal. Stud Fam Plann. 2007;38(1):35-46.

12. Shakya HB, Dasgupta A, Ghule M, Battala M, Saggurti N, Donta B, et al. Spousal discordance on reports of contraceptive communication, contraceptive use, and ideal family size in rural India: a cross-sectional study. BMC Womens Health. 2018;18(1):147.

13. Uddin J, Pulok MH, Sabah MN. Correlates of unmet need for contraception in Bangladesh: does couples' concordance in household decision making matter? Contraception. 2016;94(1):18-26.

14. Singh A, Becker S. Concordance between partners in desired waiting time to birth for newlyweds in India. J Biosoc Sci. 2012;44(1):57-71. 
15. Diro CW, Afework MF. Agreement and concordance between married couples regarding family planning utilization and fertility intention in Dukem, Ethiopia. BMC Public Health. 2013;13:903.

16. Tilahun T, Coene G, Temmerman M, Degomme O. Spousal discordance on fertility preference and its effect on contraceptive practice among married couples in Jimma zone, Ethiopia. Reprod Health. 2014;11:27.

17. Donta B, Nair S, Saggurti N, Ghule M, Madhusudana B, Dasgupta A, Gajanan V, Silverman J, Raj A. The importance of husbands' engagement in family planning discussion to promote contraception use for birth spacing in rural India. Asia-Pacific Population J. 2016;31 (2):5-20.

18. Ghule M, Raj A, Palaye P, Dasgupta A, Nair S, Saggurti N, Battala M, Balaiah D. Barriers to contraceptive methods among rural young married couples in Maharashtra, India: Qualitative findings. Asian J Res Soc Sci Humanit. 2015;5(6):18-33.

19. Raj A, Ghule M, Ritter J, Battala M, Gajanan V, Nair S, et al. Cluster randomized controlled trial evaluation of a gender equity and family planning intervention for married men and couples in rural India. PLOS ONE. 2016;11(5): e0153190.

20. Jejeebhoy SJ, Santhya KG, Zavier AJ. Demand for contraception to delay first pregnancy among young married women in India. Stud Fam Plann. 2014;45(2):183-201.

21. Doyle K, Levtov RG, Barker G, Bastian GG, Bingenheimer JB, Kazimbaya $S$, et al. Gender-transformative Bandebereho couples' intervention to promote male engagement in reproductive and maternal health and violence prevention in Rwanda: findings from a randomized controlled trial. PLOS ONE. 2018;13(4): e0192756.

22. Lundgren $\mathrm{R}$, Cachan J, Jennings V. Engaging men in family planning services delivery: experiences introducing the Standard Days Method(R) in four countries. World Health Popul. 2012;14(1):44-51.

23. Mwaikambo L, Speizer IS, Schurmann A, Morgan G, Fikree F. What works in family planning interventions: a systematic review. Stud Fam Plann. 2011;42(2):67-82.

24. Bandura A. Health promotion by social cognitive means. Health Educ Behav. 2004;31(2):143-64.

25. Sedgh G, Ashford L, Hussain R. Unmet need for contraception in developing countries: examining women's reasons for not using a method. New York: Guttmacher Institute; 2016.
26. IIPS \& ICF. National Family Health Survey (NFHS-4) 2015-16. India: Mumbai; 2017.

27. Dixit A, Averbach S, Yore J, Kully G, Ghule M, Battala M, et al. A gender synchronized family planning intervention for married couples in rural India: study protocol for the CHARM2 cluster randomized controlled trial evaluation. Reprod Health. 2019;16(1):88.

28. Hubacher D, Trussell J. A definition of modern contraceptive methods. Contraception. 2015;92(5):420-1.

29. Zou G. A modified poisson regression approach to prospective studies with binary data. Am J Epidemiol. 2004;159(7):702-6.

30. Zou GY, Donner A. Extension of the modified Poisson regression model to prospective studies with correlated binary data. Stat Methods Med Res. 2013;22(6):661-70.

31. StataCorp. Statistical Software: Release 14.0. College Station, TX: Stata Corporation; 2016.

32. Mumford SL, Sapra KJ, King RB, Louis JF, Buck Louis GM. Pregnancy intentions-a complex construct and call for new measures. Fertil Steril. 2016;106(6):1453-62.

33. Aiken ARA, Borrero S, Callegari LS, Dehlendorf C. Rethinking the pregnancy planning paradigm: unintended conceptions or unrepresentative concepts? Perspect Sex Reprod Health. 2016;48(3):147-51.

34. Hinson L, Edmeades J, Murithi L, Puri M. Developing and testing measures of reproductive decision-making agency in Nepal. SSM Popul Health. 2019:9:100473.

35. Ghuman SJ, Lee HJ, Smith HL. Measurement of women's autonomy according to women and their husbands: Results from five Asian countries. Soc Sci Res. 2006; 35(1):1-28.

\section{Publisher's Note}

Springer Nature remains neutral with regard to jurisdictional claims in published maps and institutional affiliations.
Ready to submit your research? Choose BMC and benefit from:

- fast, convenient online submission

- thorough peer review by experienced researchers in your field

- rapid publication on acceptance

- support for research data, including large and complex data types

- gold Open Access which fosters wider collaboration and increased citations

- maximum visibility for your research: over $100 \mathrm{M}$ website views per year

At $\mathrm{BMC}$, research is always in progress.

Learn more biomedcentral.com/submissions 